\title{
Properties and management of acid sulfate soils in Southeast Asia for sustainable cultivation of rice, oil palm, and cocoa
}

\begin{abstract}
Acid sulfate soils occur sporadically in the coastal plains of countries throughout the globe. The soils are characterized by a low $\mathrm{pH}$ and the presence of sulfuric horizon, overlying sulfidic materials, mostly pyrite (FeS2). This pyrite is readily oxidized when the soils are drained to make way for development (e.g., agriculture). During the process of pyrite oxidation, a straw-yellow mineral called jarosite is formed and eventually high acidity and toxic aluminum are released into the environment, affecting crop growth. This chapter reviews the studies conducted in Southeast Asia on the management of soils for sustainable crop production. Some of the soils are utilized for the cultivation of rice, oil palm, and cocoa with mixed success because of their inherently low fertility, and Al and/or Fe toxicity. For rice cultivation, lime, basalt, or organic fertilizer can be used to alleviate the infertility of the soils. Application of lime or basalt increases soil $\mathrm{pH}$, resulting in precipitation of inert $\mathrm{Al}$ hydroxides. Oil palm can be grown successfully on acid sulfate soils if the proper water management practice is carried out. The drains in the oil palm plantation should be designed in such a way that the excess water is removed from the area, while maintaining the water table level above the pyritic layer. Cocoa grows poorly on acid sulfate soils because of low $\mathrm{pH}$ and $\mathrm{Al}$ toxicity. However, with adequate liming, using ground magnesium limestone and organic matter, the soils can be utilized productively for cocoa production. In general, acid sulfate soils can be made productive for rice, oil palm, or cocoa cultivation by increasing soil $\mathrm{pH}$ with lime or basalt, applying organic matter, or adopting proper water management practices.
\end{abstract}

Keyword: Al toxicity; Fe toxicity; Acidity alleviation; Soil amendment; Rice cultivation; Jarosite; Pyrite 